\title{
Predictors of colorectal cancer screening awareness among people working in a hospital environment
}

\author{
Spyridon Michopoulos ${ }^{a}$, Efstathios Manios ${ }^{b}$, Helias Kourkoutas ${ }^{a}$, Konstantinos Argyriou ${ }^{a}$, \\ Georgios Leonidakis ${ }^{a}$, Evanthia Zampelia, Kimon Stamatelopoulos ${ }^{b}$, Athanasios-Meletios Dimopoulos ${ }^{b}$
}

Alexandra Hospital; National and Kapodistrian University of Athens, Medical School, Alexandra Hospital, Athens, Greece

\section{Abstract}

\begin{abstract}
Background Compliance rates for colorectal cancer (CRC) screening are much lower than those desired. Appropriate information on CRC risks and screening methods is supposed to stimulate motivation for screening. We aimed to identify parameters associated with the decision for CRC screening and colonoscopy in a population expected to have high awareness of disease prevention.

Methods In a single-center, cross-sectional study, we used an anonymous questionnaire (AQ) to record the demographics, habits and screening behavior for cancers and other common diseases of all employees older than 50 years in our hospital.

Results Among 287 active employees, 83\% ( $\mathrm{n}=237)$ answered the AQ (age 55 \pm 4 years). Thirty percent $(n=70)$ underwent colonoscopy while 17\% $(n=40)$ underwent CRC screening (39/40) colonoscopy). Comparatively, among women $97 \%$ had a Pap-smear, $92 \%$ a mammography, while among men $83 \%$ had been tested for serum prostate-specific antigen. Age, male sex, alcohol consumption and university education correlated positively with CRC screening $(\mathrm{P}<0.05$ for all). After multivariate analysis, university education remained an independent determinant of CRC screening (OR 2.488, 95\%CI 1.096-5.648; $\mathrm{P}=0.029$ ). Among subjects who had not undergone colonoscopy in the past, ignorance of the need for CRC screening (OR 0.360, 95\%CI 0.150-0.867; $\mathrm{P}=0.023$ ) and indifference to undergo such a procedure (OR $0.188,95 \% \mathrm{CI}$ 0.066-0.537; $\mathrm{P}=0.002$ ) were independent determinants for not planning a future screening colonoscopy.
\end{abstract}

Conclusions Education was the most important factor in the decision to undergo CRC screening. Colonoscopy was the preferred screening method. Ignorance of and indifference to CRC risks were the major obstacles for a future screening colonoscopy.

Keywords Colorectal cancer, screening, colonoscopy, behavior, education

Ann Gastroenterol 2017; 30 (2): 1-7

\section{Introduction}

Colorectal cancer (CRC) is an important health problem worldwide. According to an estimate of cancer incidence and mortality in Europe 436,000 new cases and 212,000 deaths were

${ }^{a}$ Gastroenterology Unit, "Alexandra” Hospital (Spyridon Michopoulos, Helias Kourkoutas, Konstantinos Argyriou, Georgios Leonidakis, Evanthia Zampeli); ${ }^{b}$ Department of Clinical Therapeutics, National and Kapodistrian University of Athens, Medical School, Alexandra Hospital (Efstathios Manios, Kimon Stamatelopoulos, Athanasios-Meletios Dimopoulos), Athens, Greece

\section{Conflict of Interest: None}

Correspondence to: Spyridon Michopoulos MD, PhD, 6 Agias Kyriakis Str., 14561 Athens, Greece, e-mail: michosp5@gmail.com

Received 02 November 2016; accepted 09 January 2016; published online 09 February 2017

DOI: https://doi.org/10.20524/aog.2017.0127 attributed to CRC [1]. In the United States, CRC is the second leading cause of cancer death and accounts for approximately $9 \%$ of cancer deaths overall [2]. Screening aims to diagnose premalignant conditions (adenomas) or early stages of disease and it appears to have had a considerable impact on reducing CRC incidence and mortality [3]. MISCAN-colon, a microsimulation model, suggests that screening may account for $53 \%$ of the observed reduction in CRC mortality [4]. The frequency of CRC screening is increasing, but remains below the desirable rates in most countries [5-7].

Most scientific societies recommend the age of 50 to begin CRC screening in an asymptomatic population, but there is uncertainty concerning the most cost-effective strategy [8-10]. Colonoscopy is a key tool in all CRC screening programs, either as the initial method or as a method to complement another positive screening test. The American College of Gastroenterologists recommends that quality colonoscopy should be offered first to average-risk population aged $\geq 50$ years and other screening tests should only be used in cases of unavailability or patient's unwillingness [11]. It 
is estimated that in the USA the contribution of screening to the decline of CRC mortality in the examined population is greater than $50 \%$, while the majority of CRC deaths are attributed to nonscreening [12,13]. Recently, a Canadian study confirmed that undergoing a colonoscopy within the previous 10 years provides substantial protective benefit for average-risk individuals aged over 60 years [14].

Worldwide, there are different approaches towards CRC screening that can be summarized as either organized or opportunistic methods or not screening at all [15]. Greece is classified among the countries with an opportunistic screening approach delivered outside an organized screening program. However, colonoscopy is an acceptable method reimbursed by the National Health System for those willing to be screened.

The efficacy of screening depends on many parameters, but for a common disease the main parameter for a good test is the compliance of the population. Data concerning CRC screening in Greece are scarce. In a self-reported questionnaire among a sample of Greek primary care physicians, the rate of recommending CRC screening to their patients was very low, while the presence of a regular primary physician and knowledge of CRC risks were very important discriminators influencing screening status [16,17]. In addition, financial considerations can be a significant barrier to screening [18]. In the USA, endoscopic CRC screening has increased during the last decade in the higher socioeconomic group, while this is not the case for those with low educational and socioeconomic level [19]. However, there are data showing that physicians (as patients) are less likely than the general population to adhere to specific guidelines [20].

The aim of our study was to examine whether a population supposed to be aware of the CRC problem had had any type of CRC screening. In this setting, we aimed to assess the particular place of colonoscopy and to compare characteristics between those who participated in the screening procedures and those who did not.

\section{Patients and methods}

This cross-sectional study was conducted during a threemonth period (September-November 2014). The targeted population was the staff aged more than 50 years of a tertiary hospital, the "Alexandra" University Hospital. The list of employees was provided by the hospital personnel office after approval of the protocol by the local Scientific and Ethical committee and with the final permission of the Hospital Board. An anonymous questionnaire (AQ) was distributed on a personal basis and each person receiving the AQ was marked on the list. The AQs were collected in a ballot box and a second mark was added beside the same name on the list when an employee dropped the AQ in the box.

\section{Questionnaire}

To evaluate whether the population under evaluation had different characteristics influencing its preference to be screened for CRC or not, we developed a questionnaire which consisted of two parts: 1) asking for demographic characteristics, educational level, professional activities, as well as medical history information; and 2) evaluating whether the patient participated in screening programs for common diseases. This second part had an additional section addressing questions separately for performing screening tests specific to men and women. A special part asked if the person has had CRC screening, as well as the screening method used, and finally for those who did not have a colonoscopy the reasons for this declination. All subjects were asked if they planned to have a colonoscopy in the future. The questionnaire was written in Greek and printed on two sides of an A4 sheet. It was decided to make the survey anonymous in order to ease and encourage most of the working personnel in the hospital to participate.

\section{Statistical analysis}

Statistical comparisons were performed between subjects who had undergone a screening colonoscopy and those who had not, as well as between individuals who were willing or not to undergo a screening colonoscopy in the future. Dichotomous variables were compared using the $\chi^{2}$-test and continuous variables using the independent $t$-test. Multivariate analyses were performed with the use of logistic regression to identify predictor variables for subjects who performed a screening colonoscopy and for those who were willing to perform it in the future. In the initial univariate analysis, a threshold of $\mathrm{P}<0.1$ (because of the risk of developing a type 2 error due to low statistical power in such an analysis) was used to identify candidate variables for inclusion in the final model. All covariates included in the final models were tested for interactions with each other. Because the tolerance values for each covariate were less than 0.5 , no correction for the collinearity of data was necessary. In the final multivariate analysis, statistical significance was achieved if $\mathrm{P}$ was $<0.05$. The Statistical Package for Social Science, version 23.0 for Windows (SPSS Inc., Chicago, Illinois, USA), was used for the statistical analyses.

\section{Results}

Three hundred seventy employees older than 50 years were found on the administrative list. This list included employees in a pre-retirement period or on long sick leave and therefore impossible to reach. Two hundred eightyseven active employees finally collected an AQ and 237 (83\%) dropped it in the "ballot box". The group consisted of 81 men and 156 women. The mean age was $55 \pm 4$ (50-67) years; $59 \%$ of the population were in the range $50-55$ years. Divided by profession, they consisted of $30 \%$ physicians, $43 \%$ nurses and $27 \%$ administrative employees, technical workers and other subspecialties. Thirty-six percent were smokers, $64 \%$ did not drink at all or drank occasionally, $43 \%$ consumed red meat 
more than twice per week, while $17 \%$ reported regular use of aspirin or nonsteroidal anti-inflammatory drugs.

Overall, 70 (30\%) reported having undergone colonoscopy ( $37 \%$ of men vs. $26 \%$ of women, $\mathrm{P}=0.073$ ). Thirty-nine (56\%) of the 70 persons who had undergone colonoscopy responded that this was for preventive reasons, while only 1 was tested with a fecal occult blood test and performed an additional CTcolonography. Those results led to a total of $17.0 \%$ (40 patients) who had undergone CRC screening with any method, while colonoscopy was the strong preference of this population as CRC screening method.

Cholesterol and triglycerides were evaluated at least once by $88 \%$ of the population, blood glucose by $83 \%$, while $87 \%$ had had a measurement of their arterial pressure. Among women, 97\% had a Pap-smear, 92\% a mammography and $51 \%$ a breast ultrasound, while $83 \%$ of males had been tested for serum prostate-specific antigen (PSA). There was no statistical difference between men and women for the common tests.

The main characteristics of those who had undergone a screening colonoscopy or not are summarized in Table 1 . In the univariate analysis, the parameters with a positive influence on the performance of screening colonoscopy in the past were age $(\mathrm{P}=0.003)$, male sex $(\mathrm{P}=0.009)$, alcohol consumption $(\mathrm{P}=0.026)$ and university education $(\mathrm{P}=0.001)$. It is notable that 70 of the $87(81 \%)$ subjects with a university education were physicians (Table 1). The aforementioned variables were included in the multivariate logistic regression analysis (Table 2). The only significant independent predictor for undergoing screening colonoscopy was university education (OR 2.488, 95\%CI 1.096-5.648; $\mathrm{P}=0.029$ ).

The 167 subjects who had never undergone a colonoscopy (70\%) answered the part of the questionnaire concerning the reasons why they had not undergone screening. Twenty-seven percent of them reported that they were unaware of the need to be screened for CRC. Other reasons for not undergoing colonoscopy were fear $(17 \%)$, shame $(10 \%)$, indifference (16\%), other priorities (23\%) and other (7\%). Fear and shame were more prevalent among women, while more men were indifferent, and stated that they had "other priorities" and they "didn't know". There were no statistical differences between men and women regarding the reasons leading them not to undergo a screening colonoscopy (Fig. 1). Among the 39 screening colonoscopies, 12 polyps (31\%) and no CRC were found, while the 31 colonoscopies performed for non-preventive reasons found 9 polyps (29\%) and 2 CRCs (6\%).

All subjects completed the question regarding a possible future colonoscopy. One hundred sixty-two answered positively $(68 \%)$. The main characteristics of those who were willing to undergo a screening colonoscopy or not are summarized in Table 3 . In the univariate analysis, the parameters with a positive influence on the performance of a future screening colonoscopy were age $(\mathrm{P}=0.021)$, university education $(\mathrm{P}=0.001)$, being a physician $(\mathrm{P}<0.001)$ and having had a screening colonoscopy in the past $(\mathrm{P}<0.001)$. Concerning the reasons for not performing colonoscopy in the past and the attitude to a future colonoscopy, indifference $(\mathrm{P}=0.003)$ and the fact that "I didn't know about it" $(\mathrm{P}=0.015)$ were negatively
Table 1 Baseline characteristics of the study population, separated into those who had and those who had not previously undergone a screening colonoscopy

\begin{tabular}{|c|c|c|c|}
\hline Variable & $\begin{array}{c}\begin{array}{c}\text { Screening } \\
\text { colonoscopy } \\
\mathrm{n}=39\end{array}\end{array}$ & $\begin{array}{c}\text { No screening } \\
\text { colonoscopy } \\
n=198\end{array}$ & P-value \\
\hline Age $\pm S D$ (years) & $57 \pm 5$ & $55 \pm 4$ & 0.003 \\
\hline Male sex (\%) & 54 & 30 & 0.009 \\
\hline $\mathrm{BMI} \pm \mathrm{SD}\left(\mathrm{kg} / \mathrm{m}^{2}\right)$ & $28 \pm 7$ & $27 \pm 5$ & 0.558 \\
\hline Smoking (\%) & 30 & 37 & 0.555 \\
\hline Alcohol (\%) & 53 & 33 & 0.026 \\
\hline University education (\%) & 62 & 32 & 0.001 \\
\hline Physicians (\%) & 55 & 26 & 0.001 \\
\hline Use of aspirin or NSAIDs & 25 & 16 & 0.225 \\
\hline $\begin{array}{l}\text { Preventive tests } \\
\text { All subjects (\%) (PSA test, } \\
\text { Pap test, mammography, } \\
\text { breast ultrasound) }\end{array}$ & 97 & 90 & 0.212 \\
\hline Men (PSA test) (\%) & 95 & 70 & 0.018 \\
\hline $\begin{array}{l}\text { Women (\%) (Pap test, } \\
\text { mammography, breast } \\
\text { ultrasound) }\end{array}$ & 100 & 99 & 1.000 \\
\hline
\end{tabular}

Table 2 Multivariate logistic regression analysis of factors associated with the performance of screening colonoscopy

\begin{tabular}{lccc}
\hline Variable & OR $(95 \% \mathrm{CI})$ & Wald & P-value \\
\hline Age & $1.057(0.972-1.150)$ & 1.671 & 0.196 \\
Male sex & $0.518(0.240-1.119)$ & 2.802 & 0.094 \\
Alcohol & $1.562(0.728-3.353)$ & 1.308 & 0.253 \\
$\begin{array}{l}\text { University } \\
\text { education (\%) }\end{array}$ & $2.488(1.096-5.648)$ & 4.753 & 0.029 \\
\hline
\end{tabular}

OR, odds ratio; 95\%CI, 95\% confidence interval

associated, whereas the fact that "I knew about it but I had other priorities" $(\mathrm{P}=0.002)$ was positively associated with the possibility of performing a future colonoscopy. Among the 39 screening colonoscopies, 36 (92\%) answered positively regarding a future colonoscopy ( 2 negatively and 1 did not answer), while among the 31 colonoscopies performed for non-preventive reasons only $21(68 \%)$ answered positively (6 negatively and 3 did not answer), the latter group responding similarly to the average population. Twenty-four percent of those who answered positively concerning a future colonoscopy had had a screening colonoscopy while only $1 \%$ with a past screening colonoscopy answered negatively regarding a future colonoscopy (Table 3).

In the multivariate logistic regression analysis of factors associated with the performance of a future screening colonoscopy among subjects who had not undergone colonoscopy in the past, independent predictors were ignorance of the need for CRC screening (OR 0.360, 95\%CI 0.150-0.867; 
$\mathrm{P}=0.023)$ and indifference to undergo such a procedure (OR 0.188, 95\%CI 0.066-0.537; $\mathrm{P}=0.002$ ) (Table 4).

\section{Discussion}

The population included in our study does not represent a typical sample of the Greek population. Instead, we studied a specific population with characteristics expected to positively influence a predilection for CRC screening and the practice of screening colonoscopy in particular. This sample consisted of employees in a tertiary hospital where screening colonoscopy under conscious sedation has been practiced for many years. The large majority among them are physicians or nurses, who are consequently aware of the dangers of CRC and of the screening methods applied for its prevention. In addition, our hospital operates two big university clinics, an oncology and a gynecology-oncology clinic, which occupy a large part of the personnel, thus rendering the familiarity with screening programs even more powerful. The age was appropriate for the initiation of CRC screening (50-67 years), with more than half in the range of 50-55 years. A large percentage (83\%) agreed to complete the AQ and drop it into the "ballot box". In a 2-year study (2009-10) conducted in a semi-rural area in central Greece, 6536 subjects aged $45-80$ years were called after intense advertisement to participate in a free screening colonoscopy program. Only 402 (6.2\%) responded positively to this call and underwent colonoscopy (data published on the internet site of the Hellenic Foundation of Gastroenterology and Nutrition, Patroklos Study, eligast.gr). In our population, $17 \%$ had undergone CRC screening, all but 1 with colonoscopy. This is much better than the above mentioned disappointing percentage in Central Greece, but it remains low for a very sensitive and informed population, far below the minimum $45 \%$ and the desirable $65 \%$ recommended by the European Commission [21]. Surprisingly, a large percentage reported that they did not know that they had to undergo a CRC screening test after the age of 50 (24\%), 12\% among them were physicians. Comparatively, almost all women (97\%) had had a Pap-smear and a substantial percentage (93\%) one or two tests for breast cancer. In addition $83 \%$ of men had performed a PSA blood level examination, a test much less well validated for prostatic cancer than the screening tests for CRC. However, in contrast to women's behavior regarding CRC screening, which was not influenced by having undergone another screening test, we found that men who had been tested for PSA were more willing to undergo CRC screening. The same result was found in another earlier study examining the relation between prostate and CRC screening [22]. In contrast, an uptake to CRC screening related to the adherence with either cervical cancer or breast cancer screening in women was not found in our study [23]. An additional advantage of our population was that all were living in the same big city. Living in a rural area or not could influence access to CRC screening, probably reflecting the great diversities among different health systems [24,25]. Non-insurance, cost and general lack of access to health

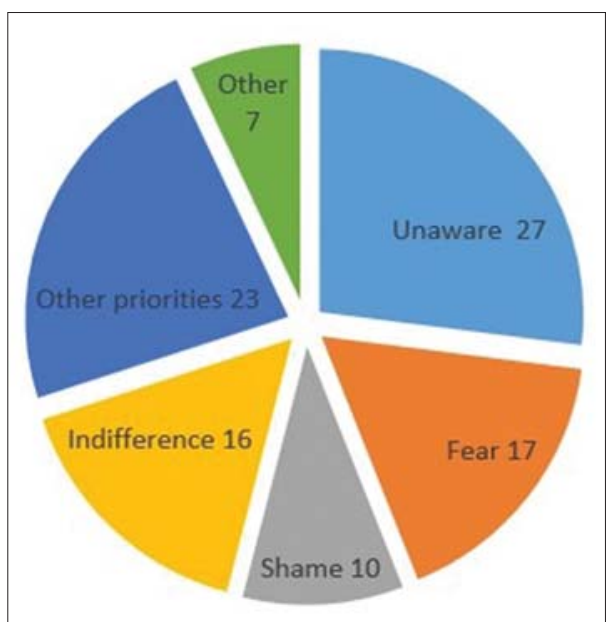

Figure 1 Schematic representation of reported reasons among those who had not undergone colorectal cancer (CRC) screening (\%): $27 \%$ reported that they were "unaware" of the need to be screened for CRC. Other reasons were "fear" (17\%), "shame" (10\%), "indifference" (16\%), "other priorities" (23\%) and "other" (7\%). Fear and shame were more prevalent among women, while more men were indifferent, and stated that they had "other priorities" or that they "didn't know". However, no statistically significant difference was found between the sexes for any specific reason

Table 3 Baseline characteristics of the study population according to the decision to perform a future screening colonoscopy

\begin{tabular}{lccc}
\hline Variable & $\begin{array}{c}\text { Future } \\
\text { colonoscopy } \\
\text { (yes) } \\
\mathrm{n}=162\end{array}$ & $\begin{array}{c}\text { Future } \\
\text { colonoscopy } \\
\text { (no) }\end{array}$ & P-value \\
$\mathrm{n}=75$ & \\
\hline Age \pm SD (years) & $56 \pm 5$ & $54 \pm 4$ & 0.021 \\
\hline Male sex (\%) & 37 & 33 & 0.651 \\
BMI \pm SD (kg/m ${ }^{2}$ ) & $27 \pm 6$ & $27 \pm 4$ & 0.279 \\
Smoking (\%) & 36 & 36 & 1.000 \\
Alcohol (\%) & 37 & 37 & 1.000 \\
\hline University education (\%) & 44 & 20 & 0.001 \\
Physicians (\%) & 39 & 15 & $<0.001$ \\
Screening colonoscopy in & 24 & 1 & $<0.001$ \\
the past (\%) & & & \\
Reasons for not & & & \\
performing colonoscopy & & & \\
Didn't know & 19 & 38 & 0.015 \\
Afraid & 17 & 15 & 0.824 \\
Ashamed & 13 & 5 & 0.163 \\
Indifferent & 9 & 28 & 0.003 \\
Other priorities & 32 & 10 & 0.002 \\
Other reasons & 10 & 5 & 0.366 \\
\hline
\end{tabular}

$B M I$, body mass index; SD, standard deviation

care were reported as main reasons for non-access to CRC screening $[26,27]$. None of the abovementioned reasons was valid for our population. A university education was the only significant independent predictor for undergoing screening colonoscopy in the multivariate logistic regression analysis. 
Table 4 Multivariate logistic regression analysis of factors associated with the performance of future screening colonoscopy in subjects who had not previously undergone colonoscopy

\begin{tabular}{lccc}
\hline Variable & OR (95\% CI) & Wald & P-value \\
\hline Age & $1.019(0.929-1.118)$ & 0.164 & 0.686 \\
$\begin{array}{l}\text { University } \\
\text { education }\end{array}$ & $2.190(0.893-5.371)$ & 2.936 & 0.087 \\
$\begin{array}{l}\text { Subjects “didn’t } \\
\text { know" }\end{array}$ & $0.360(0.150-0.867)$ & 5.195 & 0.023 \\
$\begin{array}{l}\text { Subjects were } \\
\text { "indifferent" }\end{array}$ & $0.188(0.066-0.537)$ & 9.719 & 0.002 \\
$\begin{array}{l}\text { Subjects had } \\
\text { "other priorities" }\end{array}$ & $1.839(0.626-5.403)$ & 1.227 & 0.268 \\
\hline $\begin{array}{l}\text { OR, odds ratio; 95\% CI, 95\% confidence ingerval } \\
\text { (1) }\end{array}$ & & \\
\hline
\end{tabular}

Education has also been found to be an important factor influencing CRC screening in several studies: the lower the education level the lower the participation [28-30]. Income was not measured directly, but because all the participants were employees we can deduce with considerable accuracy that the higher the education, the higher the income. Age and male sex were found in the univariate analysis to be important factors influencing screening colonoscopy. Older people ( $>65$ years) are more likely to undergo CRC screening both in the USA and in Europe [31,32]. In our population, most patients were aged between $50-55$ years. However, this tendency for older individuals to have undergone screening colonoscopy more often than younger was reproduced in our study. Male sex was also found to be a predictive factor for CRC screening in other studies, but less often than age $[33,34]$. We have no satisfactory explanation for our finding: for example physicians and persons with higher education were equally distributed as to sex. In addition, because almost all women had had a Pap-test and screening for breast cancer, we would expect that there would be no sex-related difference; however, this was not the case.

Interpretation of individual or collective behaviors for subjects participating or not in screening programs is a difficult and sometimes slippery task. Different strategies to make screening more attractive have been used with mixed results. In a meta-analysis examining the effectiveness of approaches for improving adherence to adult immunization and cancer screening, organizational change interventions were the most potent to achieve the best results [35]. Many speculations have been formulated concerning either the reasons for non-participation or the methods of attracting people into CRC screening and screening colonoscopy in particular. For example, different types of financial incentives seem not to improve CRC screening participation, unlike the screening uptake for other cancers [36,37].

In our study, among those who had never undergone a colonoscopy $27 \%$ reported that they were unaware that CRC screening should be performed after the age of 50. This percentage was lower than that previously reported even among previously screened populations, probably reflecting the high level of information on medical subjects among our population as a result of their working environment [17]. All subjects were questioned about their willingness to perform a future colonoscopy. Age, university education, being a physician and having had a screening colonoscopy in the past positively influenced the decision for a future screening colonoscopy in the univariate analysis. Among subjects who had not undergone colonoscopy, ignorance of and indifference to perform a CRC screening colonoscopy were negatively associated with a future colonoscopy in the multivariate logistic regression analysis.

In the USA, the prevalence of CRC screening has increased since 2000. This was due almost exclusively to an increase in colonoscopies, which tripled during the past decade from 19\% to $55 \%[38,39]$. Patients with previous experience of colorectal screening preferred future screening, although patients who should be very motivated, such as those with previously detected adenoma, were not always compliant with follow-up colonoscopy [40,41].

In our study, those who had had a screening colonoscopy were much more positive about a future colonoscopy $(92 \%)$, while among those who had had a colonoscopy for nonpreventive reasons the willingness to undergo another procedure reached only the same percentage as in the overall population (68\%). Although there are no data to explain this behavior, it probably reflects the differences between those who have the willingness and the conviction to engage in prevention and those who have not. This underlines the need for better promotion in order to spotlight the benefits of CRC screening and to motivate people to enter screening programs. In addition, a previous non-negative experience should help maintain the motivation to be screened for CRC, but we have no data to support this. Interestingly, in a Greek study addressing a questionnaire to medical students in their fourth study year, only $69 \%$ considered CRC as an important public health problem, $85 \%$ would prefer a method other than colonoscopy for screening, and 53\% believed that colonoscopy is painful [42]. These results, combined with ours from informed adults over 50 years old, underpin the need for better education about CRC as a public health problem and the usefulness of CRC screening as part of the very basic phase of physicians' studies, as well as a policy promoting painless colonoscopy.

In summary, in our cross-sectional study of a specific population older than 50 years, working in a tertiary hospital, we found that a non-negligible percentage declared that they were not aware of the need for CRC screening, which was practiced much less than screening for other common diseases or cancers. However, among the screened population almost all had preferred colonoscopy as screening method. Education was the most important factor influencing willingness to undergo CRC screening. Ignorance and indifference to the CRC risks were the major obstacles to a future screening colonoscopy, while experience with a previous colonoscopy facilitated the decision for a future screening colonoscopy. Further studies aiming to effectively intervene in modifiable behavioral factors must be undertaken in order to make CRC screening and colonoscopy more attractive to populations who are ignorant of or indifferent to the dangers of CRC. 


\section{Summary Box}

\section{What is already known:}

- Colorectal cancer (CRC) screening substantially reduces mortality

- Implementation of CRC screening is suboptimal, even in well-organized societies

- Screening for other cancers shows better compliance compared to CRC

- Decisions about screening and adherence to screening programs are multifactorial

\section{What the new findings are:}

- CRC screening is much less well implemented in a well-informed Greek population compared to screening for other cancer and common diseases

- Education is the major factor influencing decisions about CRC screening

- Colonoscopy is the preferred screening method in this population

- Ignorance and indifference to CRC risks are the major barriers to a future screening colonoscopy

\section{References}

1. Ferlay J, Parkin DM, Steliarova-Foucher E. Estimates of cancer incidence and mortality in Europe in 2008. Eur J Cancer 2010;46:765-781.

2. Siegel R, Ma J, Zou Z, Jemal A. Cancer statistics, 2014. CA Cancer J Clin 2014;64:9-29.

3. Zauber AG, Lansdorp-Vogelaar I, Knudsen AB, Wilschut J, van Ballegooijen M, Kuntz KM. Evaluating test strategies for colorectal cancer screening: a decision analysis for the U.S. Preventive Services Task Force. Ann Intern Med 2008;149:659-669.

4. Edwards BK, Ward E, Kohler BA, et al. Annual report to the nation on the status of cancer, 1975-2006, featuring colorectal cancer trends and impact of interventions (risk factors, screening, and treatment) to reduce future rates. Cancer 2010;116:544-573.

5. Shahidi NC, Homayoon B, Cheung WY. Factors associated with suboptimal colorectal cancer screening in US immigrants. Am J Clin Oncol 2013;36:381-387.

6. Centers for Disease Control and Prevention (CDC). Vital signs: colorectal cancer screening test use--United States, 2012. MMWR Morb Mortal Wkly Rep 2013;62:881-888.

7. Hoff, G, Dominitz JA. Contrasting US and European approaches to colorectal cancer screening: which is best? Gut 2010;59:407-414.

8. Levin B, Lieberman DA, McFarland B, et al; American College of Radiology Colon Cancer Committee. Screening and surveillance for the early detection of colorectal cancer and adenomatous polyps, 2008: a joint guideline from the American Cancer Society, the US Multi-Society Task Force on Colorectal Cancer, and the American College of Radiology. Gastroenterology 2008;134:15701595.

9. Leddin D, Hunt R, Champion M, et al; Canadian Digestive Health Foundation. Canadian Association of Gastroenterology and the Canadian Digestive Health Foundation: Guidelines on colon cancer screening. Can J Gastroenterol 2004;18:93-99.

10. von Karsa L, Patnick J, Segnan N, et al; European Colorectal Cancer Screening Guidelines Working Group. European guidelines for quality assurance in colorectal cancer screening and diagnosis: overview and introduction to the full supplement publication. Endoscopy 2013;45:51-59.

11. Rex DK, Johnson DA, Anderson JC, Schoenfeld PS, Burke CA, Inadomi JM; American College of Gastroenterology. American College of Gastroenterology guidelines for colorectal cancer screening 2009 [corrected]. Am J Gastroenterol 2009;104:739-750.

12. Zauber AG. The impact of screening on colorectal cancer mortality and incidence: has it really made a difference? Dig Dis Sci 2015;60:681-691.

13. Meester RG, Doubeni CA, Lansdorp-Vogelaar I, et al. Colorectal cancer deaths attributable to nonuse of screening in the United States. Ann Epidemiol 2015;25:208-213.

14. Stock D, Paszat LF, Rabeneck L. Colorectal cancer mortality reduction is associated with having at least 1 colonoscopy within the previous 10 years among a population-wide cohort of screening age. Gastrointest Endosc 2016;84:133-141.

15. Schreuders EH, Ruco A, Rabeneck L, et al. Colorectal cancer screening: a global overview of existing programmes. Gut 2015;64:1637-1649.

16. Xilomenos A, Mauri D, Kamposioras K, et al; Panhellenic Association for Continual Medical Research (PACMeR). Colorectal cancer screening awareness among physicians in Greece. BMC Gastroenterol 2006;6:18.

17. Harewood GC, Wiersema MJ, Melton LJ 3rd. A prospective, controlled assessment of factors influencing acceptance of screening colonoscopy. Am J Gastroenterol 2002;97:3186-3194.

18. Perkins A, Nicholls K, Shaw T, Liu G, Molokhia E. Attitudes toward colorectal cancer screening in the digital age: a survey of practices and attitudes among screening-eligible Alabamians. South Med J 2013;106:462-467.

19. Bandi P, Cokkinides V, Smith RA, Jemal A. Trends in colorectal cancer screening with home-based fecal occult blood tests in adults ages 50 to 64 years, 2000-2008. Cancer 2012;118:5092-5099.

20. Berk J, Mills B, Varma S. Physician, heal thyself: health maintenance behaviors among physicians. Tex Med 2014;110:e1.

21. Moss S, Ancell-Park R, Brenner H. Evaluation and interpretation of screening outcomes. In: Segnan N, Patnick J, von Karsa L (eds). European Guidelines for Quality Assurance in Colorectal Cancer Screening and Diagnosis, European Union, 1st edition, 2010, pp. 71-102.

22. Carlos RC, Underwood W 3rd, Fendrick AM, Bernstein SJ. Behavioral associations between prostate and colon cancer screening. J Am Coll Surg 2005;200:216-223.

23. Carlos RC, Fendrick AM, Ellis J, Bernstein SJ. Can breast and cervical cancer screening visits be used to enhance colorectal cancer screening? J Am Coll Radiol 2004;1:769-776.

24. Blom J, Yin L, Lidén A, et al. Toward understanding nonparticipation in sigmoidoscopy screening for colorectal cancer. Int J Cancer 2008;122:1618-1623.

25. Faruque FS, Zhang X, Nichols EN, et al. The impact of preventive screening resource distribution on geographic and populationbased disparities in colorectal cancer in Mississippi. BMC Res Notes 2015;8:423.

26. Beydoun HA, Beydoun MA. Predictors of colorectal cancer screening behaviors among average-risk older adults in the United States. Cancer Causes Control 2008;19:339-359.

27. Holden DJ, Jonas DE, Porterfield DS, Reuland D, Harris R. Systematic review: enhancing the use and quality of colorectal cancer screening. Ann Intern Med 2010;152:668-676.

28. Meissner HI, Breen N, Klabunde CN, Vernon SW. Patterns of colorectal cancer screening uptake among men and women in the United States. Cancer Epidemiol Biomarkers Prev 2006;15:389-394. 
29. von Wagner C, Knight K, Steptoe A, Wardle J. Functional health literacy and health-promoting behaviour in a national sample of British adults. J Epidemiol Community Health 2007;61:1086-1090.

30. Gimeno-García AZ, Quintero E, Nicolás-Pérez D, Parra-Blanco A, Jiménez A. Colorectal cancer screening in a Spanish population. Med Clin (Barc) 2009;133:736-740.

31. Thrasher JF, Cummings KM, Michalek AM, Mahoney MC, Moysich KB, Pillittere DM. Colorectal cancer screening among individuals with and without a family history. $J$ Public Health Manag Pract 2002;8:1-9.

32. Segnan N, Senore C, Andreoni B, et al; SCORE2 Working Group-Italy. Randomized trial of different screening strategies for colorectal cancer: patient response and detection rates. J Natl Cancer Inst 2005;97:347-357.

33. Zorzi M, Da Re F, Mantellini P, et al; Italian colorectal cancer screening survey group. Screening for colorectal cancer in Italy: 2011-2012 survey. Epidemiol Prev 2015;39:93-107.

34. Rim SH, Joseph DA, Steele CB, Thompson TD, Seeff LC; Centers for Disease Control and Prevention (CDC). Colorectal cancer screening-United States, 2002, 2004, 2006, and 2008. MMWR (Suppl) 2011;60:42-46.

35. Stone EG, Morton SC, Hulscher ME, et al. Interventions that increase use of adult immunization and cancer screening services: a meta-analysis. Ann Intern Med 2002;136:641-651.

36. Kullgren JT, Dicks TN, Fu X, et al. Financial incentives for completion of fecal occult blood tests among veterans: a 2-stage, pragmatic, cluster, randomized, controlled trial. Ann Intern Med 2014;161:S35-S43.

37. Gupta S, Miller S, Koch M, et al. Financial incentives for promoting colorectal cancer screening: a randomized, comparative effectiveness trial. Am J Gastroenterol 2016;111:1630-1636.

38. Schenck AP, Peacock SC, Klabunde CN, Lapin P, Coan JF, Brown ML. Trends in colorectal cancer test use in the medicare population, 1998-2005. Am J Prev Med 2009;37:1-7.

39. National Center for Health Statistics. Health, United States, 2012: With Special Feature on Emergency Care. Hyattsville, MD, 2013.

40. Sheikh RA, Kapre S, Calof OM, Ward C, Raina A. Screening preferences for colorectal cancer: a patient demographic study. South Med J 2004;97:224-230.

41. Murphy CC, Lewis CL, Golin CE, Sandler RS. Underuse of surveillance colonoscopy in patients at increased risk of colorectal cancer. Am J Gastroenterol 2015;110:633-641.

42. Papanikolaou IS, Sioulas AD, Kalimeris S, et al. Awareness and attitudes of Greek medical students on colorectal cancer screening. World J Gastrointest Endosc 2012;4:513-517. 